\title{
OS VALORES PATRIMONIAIS DA PAISAGEM CULTURAL: UMA ABORDAGEM PARA O PROCESSO DE INTERVENÇÃO
}

\author{
THE HERITAGE VALUES OF CULTURAL LANDSCAPE: AN APPROACH TO THE INTERVENTION \\ PROCESS
}

\author{
SILVA, Aline de Figueirôa \\ Arquiteta e urbanista, mestranda do Programa de pós-graduação em Desenvolvimento Urbano da UFPE \\ e bolsista da UNESCO no Programa de Especialização em Patrimônio do IPHAN - Instituto do Patrimônio \\ Histórico e Artístico Nacional. E-mail: alinefigueiroa@yahoo.com.br
}

BRAGA, Anna Caroline

Arquiteta e urbanista, mestranda do Programa de pós-graduação em Desenvolvimento Urbano da UFPE. E-mail:annabrag@hotmail.com

GAMEIRO, Fabiana Gonçalves

Arquiteta e urbanista, mestranda do Programa de pós-graduação em Desenvolvimento Urbano da UFPE. E-mail: fabianagameiro@hotmail.com

LIRA, Flaviana Barreto

Arquiteta e urbanista, mestranda do Programa de pós-graduação em Desenvolvimento Urbano da UFPE. E-mail: flavianalira@hotmail.com

\section{SÁ CARNEIRO, Ana Rita}

Arquiteta, Phd em Parques Urbanos pela Oxford Brookes University, Professora da graduação em Arquitetura e Urbanismo e da Pós-graduação em Desenvolvimento Urbano da UFPE; Coordenadora do Laboratório da Paisagem e Membro do CECl - Centro de Estudos Avançados em Conservação Integrada. E-mail: anaritacarneiro@hotmail.com

MELO, Vera Mayrinck

Arquiteta, Doutora em Geografia Humana pela UFRJ, Professora da graduação em Arquitetura e Urbanismo e da Pós-graduação em Desenvolvimento Urbano da UFPE.E-mail: veramelo@hotlink.com.br

\section{RESUMO}

O texto discute o conceito de paisagem cultural com enfoque na identificação de atributos e valores que thes conferem interesse patrimonial. A paisagem cultural resulta da relação homem-natureza em determinado tempo e espaço e é composta por formas integrantes e interdependentes, constituindo um sistema vivo, dinâmico, em processo constante de desenvolvimento e substituição. Portanto, considerando essas características, como é possível preservá-la? Partindo de uma rápida reflexão sobre a noção de patrimônio, discute-se o conceito de paisagem cultural, conduzindo-se pela Geografia e como categoria do patrimônio instituída pela UNESCO. A seguir, busca-se entender quais os atributos da paisagem cultural que permitem identificá-la como patrimônio, passando à discussão dos valores patrimoniais que lhe podem ser conferidos. Conclui-se sobre a pertinência da paisagem cultural como categoria do patrimônio em nível nacional e local em favor da preservação conjunta dos bens naturais e culturais, tangíveis (materiais) e intangíveis (imateriais).

Palavras-chave: Paisagem cultural, valor patrimonial, intervenção.

\begin{abstract}
This paper discusses cultural landscape concept focusing its attributes that gives it heritage value. Cultural landscape is a result of human-environment relationship considering time and space. It joins different forms in a dynamic and live system. Based on some reflection about heritage this paper discusses the concept of cultural landscape in the field of Geography and as heritage matter according to UNESCO's point of view. It follows in understanding cultural landscape attributes to identify heritage values. Cultural landscape as heritage matter also in national and local level intends to guarantee the conservation of the natural and cultural assets, being it material and immaterial.
\end{abstract}

Key words: Cultural landscape, heritage value, intervention. 


\section{Introdução}

Atualmente assiste-se a uma rápida transformação das áreas urbanas, rurais e periurbanas, que podem levar a perdas no patrimônio natural e cultural, repercutindo na paisagem. Nesse contexto, propõe-se discutir o conceito de paisagem cultural com enfoque na identificação de atributos e valores que thes conferem interesse patrimonial, com vistas à sua preservação'.

O conceito de paisagem cultural tem base na Geografia Cultural ${ }^{2}$ como um artefato simultaneamente natural e cultural, constituída por elementos ou atributos que a tornam única e portadora de diferentes valores, os quais podem the conferir interesse patrimonial. A noção de patrimônio está ligada a três categorias: tempo, espaço e valor. Surge quando é conferido valor aos bens produzidos pelo homem, pela natureza ou decorrentes da integração entre eles, no tempo e no espaço.

Assim, o texto estrutura-se em quatro partes. A primeira apresenta a criação do conceito de patrimônio, situando a instituição da categoria paisagem cultural pela UNESCO em 1992. A segunda traz a reflexão sobre o conceito de paisagem cultural sob o enfoque da Geografia e no âmbito do patrimônio, pontuando sua inserção no pensamento preservacionista. A terceira discorre sobre os atributos ou elementos constituintes da paisagem, dos quais decorre sua feição ou aparência, porém vistos a partir de suas inter-relações. Por fim, a quarta parte discute os valores patrimoniais da paisagem cultural.

\section{O conceito de patrimônio}

Etimologicamente, o termo patrimônio advém do latim patrimonium, que significa "bens de família", "posses", deixados de pai para filho, expressando a noção de herança "ligada às estruturas familiares, econômicas e jurídicas de uma sociedade enraizada no tempo e no espaço" (Choay, 2001, p. 11), mais tarde atingindo o domínio público.

Desde sua formulação, a palavra tem atravessado uma "trajetória diferente", tornando-se um "conceito nômade" (Choay, 2001, p. 11). Primeiramente se construiu o entendimento de patrimônio histórico, significando um bem, um objeto e depois passou a designar um conjunto de bens, constituído por uma acumulação contínua.

O conceito de patrimônio histórico posteriormente se estendeu à noção de patrimônio cultural, que abrange bens materiais (tangíveis) e imateriais (intangíveis) portadores de diferentes valores: históricos, artísticos (estéticos), científicos, sociais, arqueológicos e etnográficos, entre outros. Assim, o patrimônio histórico se insere na noção maior do patrimônio cultural, que abarca outros bens aos quais sejam atribuídos valores em função da atividade humana em geral.

Nesse intervalo, com o Movimento Ecológico da década de 1970, a preservação dos bens naturais ganhou visibilidade, então designada de "ambiental", quando a natureza passou a despertar interesse patrimonial, todavia, ainda desvinculada do patrimônio cultural. É em 1992 que surge, como categoria do patrimônio, a paisagem cultural, cuja noção conjuga a preservação dos bens naturais e culturais de forma integrada.

\section{O conceito de paisagem cultural}

A paisagem é um conceito-chave da Geografia, capaz de lhe fornecer unidade como disciplina.

298 Porém, sua importância e abrangência variaram bastante na história do pensamento geográfico (Corrêa e Rosendahl, 1998, p. 8).

Corrêa e Rosendahl (1998, p. 8) identificam cinco dimensões para a paisagem geográfica: morfológica (conjunto de formas criadas pela ação da natureza e do homem), funcional (dada 
pelas relações entre suas partes), histórica (produto da ação humana no tempo), espacial (ocorre em certa área da superfície da terra) e simbólica (expressa valores, crenças e mitos).

A paisagem geográfica apresenta-se como uma noção multifacetada, mais complexa que o entendimento do senso comum, que a circunscreve à sua dimensão física (na acepção de panorama, lance abarcado pela visão) ou à sua dimensão natural (como sinônimo de natureza, longe ou mesmo livre da presença humana).

Nos anos de 1920, o geógrafo americano Carl Saver (Corrêa e Rosendahl, 1998, p. 23) define a paisagem geográfica como "uma área composta por uma associação distinta de formas, ao mesmo tempo físicas e culturais".

A paisagem cultural é, nas palavras de Saver (Corrêa e Rosendahl, 1998, p. 9), "modelada a partir de uma paisagem natural por um grupo cultural. A cultura é o agente, á área natural é o meio, a paisagem cultural o resultado". Todavia, Saver privilegiou a análise morfológica da paisagem cultural e os aspectos materiais da cultura, não considerando seus aspectos subjetivos.

No mesmo sentido, o médico e geógrafo brasileiro Josué de Castro, em 1948, utiliza a noção de paisagem cultural. Sua tese sobre a cidade do Recife originou-se da "orientação correlacionista, que procura reivindicar (...) os traços culturais da paisagem, reveladores da atuação criadora do homem, mas também os seus traços naturais, que condicionam e dirigem, até certo ponto, esta ação do fator humano" (Castro, 1948, p. 8).

O termo paisagem cultural encontra aporte no âmbito da preservação por ter sido incorporado em 1992 pela UNESCO como uma categoria do patrimônio, devido à revisão de convenção acerca do patrimônio mundial de 1972. Segundo Meneses (2002, p. 52), "A UNESCO apenas seguiu a linha traçada, desde a segunda década do século XX por geógrafos inovadores como Carl O. Saver".

Nos documentos patrimoniais entre 1962 e 1995, no entanto, pode-se perceber a ampliação do quadro de valores atribuídos à paisagem, embora esta, ora apareça explicitamente, ora sob designações como "entorno", "ambiência" ou "vizinhança", na acepção de algo "circundante". Nesse sentido, por vezes a paisagem é o próprio objeto de preservação e, em outros documentos, é a "moldura" ou o "invólucro" que protege o monumento ou o bem reconhecido como patrimônio. A paisagem é compreendida de forma genérica, carecendo de uma maior definição, o que ocorre em 1995 com a Recomendação sobre a Conservação Integrada das Áreas de Paisagens Culturais.

A Convenção sobre a Salvaguarda do Patrimônio Mundial, Cultural e Natural, da UNESCO, de 1972, ao equiparar em nível mundial o patrimônio cultural e natural de interesse para a humanidade, criou, na apreciação de Rössler (2000), "um instrumento internacional único que reconhece e protege o patrimônio natural e cultural de valor universal excepcional". Ainda segundo Rössler (2000), "com essa decisão, a convenção se transformou no primeiro instrumento jurídico internacional para identificar, proteger, conservar e legar às gerações futuras as paisagens culturais de valor universal excepcional".

O documento instituiu três tipos de bens do patrimônio cultural - os monumentos, os conjuntos e os sítios - e três do patrimônio natural - os monumentos naturais, as formações geológicas e fisiográficas e os sítios naturais (Cury, 2000, p. 178-179). Dentre os sítios do patrimônio cultural estão "as obras conjugadas do homem e da natureza" (Cury, 2000, p. 179), das quais as paisagens culturais são representantes, segundo Rössler (2000), para quem, "o termo 'paisagem cultural' inclui uma diversidade de manifestações da interação entre o homem e seu ambiente natural".

Foi em 1992, na cidade francesa de La Petite, que a UNESCO estabeleceu três classes de paisagens culturais: paisagem claramente definida, concebida e criada pelo homem, como o 
Palácio e o Jardim de Versailles, na França; paisagem essencialmente evolutiva, subdividida em relíquia (fóssil), a exemplo dos Sítios Incas no Peru, e viva, como os terraços de arroz na Ásia, e paisagem associativa, relacionada mais a fenômenos religiosos, artísticos ou culturais, do que aos traços culturais tangíveis, das quais são exemplos os montes sagrados Taishan e Huangshan na China.

Embora não explicite os valores atribuídos à paisagem cultural, a UNESCO deixa entrever um interesse artístico, histórico, social, arqueológico, religioso e utilitário, também mencionado em diversos documentos patrimoniais. Ao adjetivar as paisagens de interesse patrimonial com o qualitativo cultural, a UNESCO vincula definitivamente a paisagem à presença humana, vencendo, pois, noções ainda bastantes enraizadas de paisagem como sinônimo de "natureza" ou como "área abarcada pela visão".

Assim, a paisagem cultural converge para a atual noção de patrimônio cultural, que prepondera sobre a expressão original de patrimônio histórico, isto é, a dimensão histórica se insere na cultura. Mas, considerando que a paisagem cultural é um sistema vivo, dinâmico e em constante evolução, como é possível preservá-la? O que deve ser preservado?

\section{Os atributos da paisagem natural}

A paisagem cultural resulta da relação homem-natureza em determinado tempo e espaço. Ela é um sistema composto por formas integrantes e interdependentes, portanto, possuidora de uma qualidade orgânica. A paisagem cultural é viva, dinâmica, está em processo constante de desenvolvimento e substituição. Ela evolui de acordo com as forças naturais e as ações das sociedades humanas que nela atuam. Todavia, ao mesmo tempo em que a paisagem cultural é um sistema, ela é também uma unidade, constituída por atributos que a tornam homogênea, coesa, única e inconfundível dentro de um conjunto de paisagens.

que faz com que uma paisagem cultural tenha determinada feição ou aparência são seus atributos, ou seja, seus elementos constituintes considerados não apenas isoladamente, mas a partir de suas inter-relações.

Partindo da orientação de Delphim (2006) e da interpretação do trabalho de Cabral e Souza (2005, p. 62-63), considera-se que os atributos da paisagem cultural podem ser agrupados em três categorias: física, constituída pelo solo e relevo, clima e recursos hídricos; biológica, composta pela cobertura vegetal e pela fauna; antrópica, formada pelos produtos da ação humana, como as edificações, infra-estruturas, sítios históricos e arqueológicos.

No caso das paisagens culturais, de acordo com seus atributos serão conferidos valores que permitirão seu reconhecimento como patrimônio, os quais serão o foco da preservação. Partindo da premissa de que a paisagem cultural é dinâmica e seus atributos evolvem e se modificam pela ação natural e antrópica, o importante é garantir que os valores se mantenham ao longo do tempo para que as futuras gerações os reconheçam.

Para tanto, é necessário que a proteção das paisagens culturais seja feita através de um processo de inventariação, que the identifique os atributos, e de gestão, que controle e estabeleça limites às mudanças de uso e às intervenções a serem realizadas, para que estas não the afetem de forma significativa e as futuras gerações continuem reconhecendo os valores que elas carregam.

Sendo o tempo e o espaço variáveis dinâmicas, ao realizar um inventário, o que se tem é a

300 "fotografia" de um instante, em que estão presentes as concepções vigentes de uma sociedade e de seu comportamento acerca da natureza, bem como as relações entre ambos. A paisagem cultural continuará evoluindo ao longo do tempo, porém mantendo-se os atributos que permitiram a identificação dos valores. 
Deste modo, as intervenções a serem realizadas em uma paisagem cultural devem partir de um julgamento crítico, em que sejam considerados os atributos e sua importância para a manutenção dos valores patrimoniais. Cada paisagem cultural é um caso particular, expressa determinado caráter, o qual orientará os especialistas no processo de intervenção.

\section{Os valores da paisagem cultural}

O valor é uma construção humana e difere de categorias como o tempo e o espaço; não possui uma representação quantitativa, mas, exclusivamente qualitativa. Os valores são construídos a partir de consensos, acordos entre os homens, sendo uma categoria puramente histórica (Connor, 1999), que dá sentido ao tempo e ao espaço.

No campo do patrimônio, o jurista, filósofo e historiador Aloïs Riegl, em 1903, em "O Culto Moderno aos Monumentos", propôs uma análise da "índole" dos monumentos, seus diferentes valores e as relações entre eles. Riegl (1999) sistematiza, sob o enfoque da identificação e da classificação de valores, as posturas expressas nas obras de autores que tratavam do patrimônio no século XIX, como John Ruskin, Eugène Emmanuel Viollet-Le-Duc e Camillo Boito.

A expressão monumento advém do latim monumentum, derivado de monere, que quer dizer "advertir" ou "lembrar", significando, pois, aquilo que traz algo à lembrança; algo edificado para evocar, tocar pela emoção. Essa função memorial foi atribuída a muitas edificações, designadas de monumentos históricos, bens que, embora não tivessem sido edificados para tal, desempenhavam esse papel.

A paisagem cultural, como monumento, é um depositário de valores e detentora de um papel memorial, motivo pelo qual a categorização de Riegl (1999) the é aplicável. Com a interpretação dos documentos patrimoniais e das reflexões de Delphim (2004), Lacerda (2002) e Sales (2000) foi possível identificar outros valores atribuídos contemporaneamente à paisagem cultural, expandindo o conjunto definido por Riegl (1999). Buscou-se reunir os valores em grupos temáticos, embora sem a intenção de impor limites fixos de distinção entre eles, posto que "quase sempre, são fortemente imbricados, de difícil delimitação, uma vez que não existem separadamente" (Lacerda, 2002, p. 60).

Ao defender que toda atividade humana e todo destino humano de que se foi conservado testemunho têm o direito de reclamar para si um valor histórico, Riegl (1999) incluiu, ainda que não explicitamente ${ }^{3}$, a paisagem cultural. Ele procedeu à identificação de diversos valores presentes nos monumentos, classificando-os em: valores rememorativos, ligados à memória, história e história da arte, e valores de contemporaneidade, que surgem da satisfação das necessidades materiais e espirituais do homem contemporâneo.

Os valores rememorativos compreendem o valor de antigüidade, o valor histórico e o valor rememorativo intencionado.

O valor de antigüidade refere-se à transitoriedade das criações humanas, cujo fim é a degradação e seu reconhecimento ocorre de forma imediata, tanto por especialistas como por leigos, ao se observar o monumento. Para os defensores da manutenção desse valor, as intervenções no monumento são indesejadas, pois fogem ao seu ciclo natural de criação e destruição. A identificação desse valor ocorre face à aparência de envelhecimento e decaimento da superfície, manifesta na forma da pátina ${ }^{4}$.

Um exemplo bastante elucidativo de uma paisagem cultural em que o valor de antigüidade é rapidamente perceptível é aquela vista quando uma ruína se encontra integrada em uma área natural, a exemplo da cidade de Alcântara, no Maranhão.

O valor histórico identificado por Riegl (1999) refere-se ao fato de um monumento representar uma etapa determinada da evolução de campos criativos da humanidade. Diz respeito a tudo 
aquilo que foi conservado da atividade humana e que represente um determinado momento de sua evolução. A preservação do monumento é fundamental para que se mantenha o valor histórico e sua transmissão para as gerações vindouras.

Os engenhos de cana-de-açúcar no nordeste brasileiro são exemplos de uma paisagem cultural detentora de valor histórico, por refletir não só uma conjuntura econômica, como a organização social e os modos de vida de um período da história brasileira, manifesto num padrão compositivo que, em geral agrega, casa-grande, senzala, capela, moenda e canaviais (Figura 1).

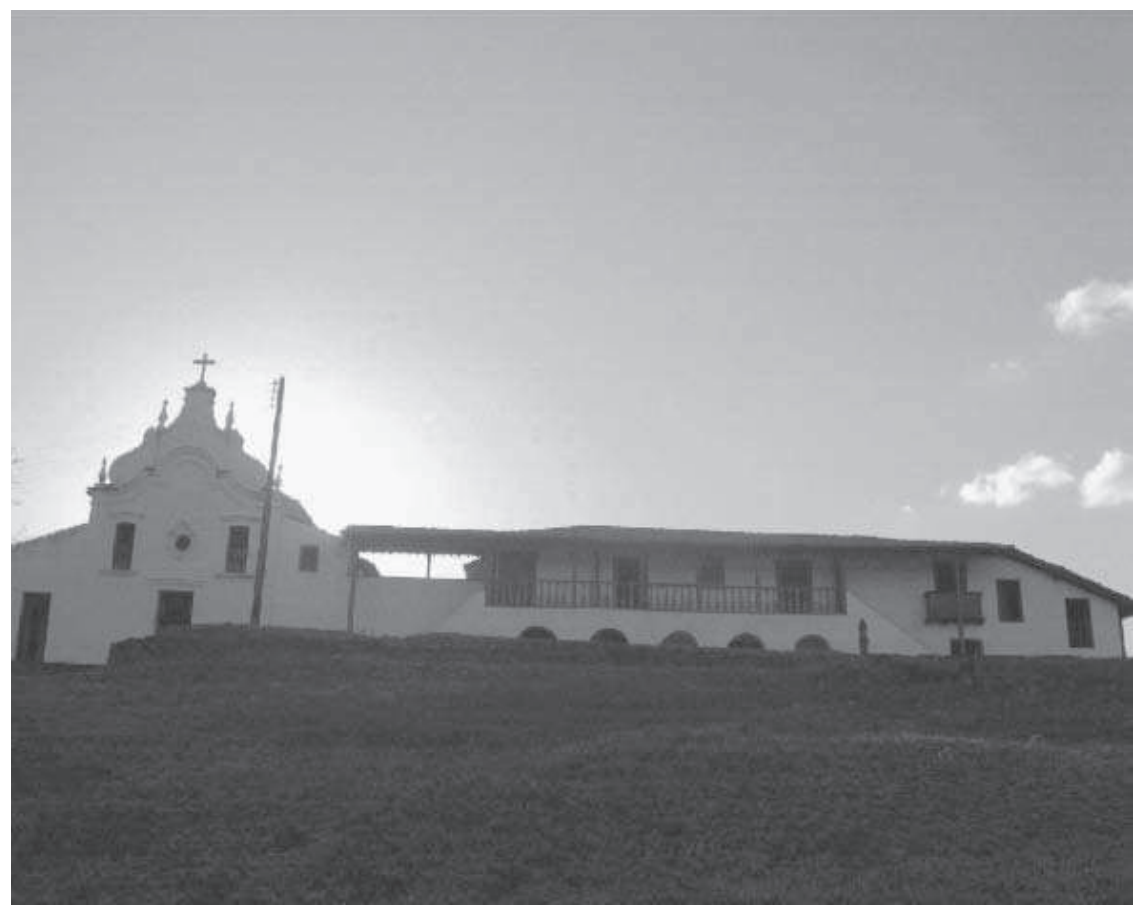

Figura 1: Engenho Poço Comprido, Vicência-PE, 2004 Crédito: Foto de Fabiana Gameiro

Algumas paisagens culturais podem ser modeladas com a intenção de se criar um lugar de memória, que remeta a algum fato ou acontecimento. A elas, em consonância com Riegl (1999), pode ser atribuído um valor rememorativo intencionado, uma vez que sua criação foi determinada tendo em vista uma função memorial deliberada.

Uma paisagem cultural na qual se identifica fortemente o valor rememorativo intencionado é a do Cristo Redentor no Rio de Janeiro. Ao olhar a estátua do Cristo a partir de diferentes locais da cidade, percebe-se claramente a mensagem que se quis transmitir com a sua concepção: a cidade sempre abençoada e protegida por seu Criador original.

No caso dos valores de contemporaneidade, Riegl (1999) identifica o valor instrumental e o valor artístico (de novidade ou relativo).

O valor instrumental ou valor de uso está relacionado à existência ou não da possibilidade de utilização do monumento para satisfação das atividades do homem contemporâneo. Os campos de arroz na China seriam um exemplo de paisagem cultural em que se identifica um valor de uso.

302 O valor artístico, segundo Riegl (1999), varia com o que ele chama de exigências da moderna vontade da arte, de pessoa para pessoa e ao longo do tempo. Segundo o autor, este valor se subdivide em dois: o valor artístico de novidade e o valor artístico relativo. $O$ valor artístico de novidade refere-se à aparência intacta e fresca da obra, com um perfeito estado de forma e cor, 
expressando um caráter de novidade. Ao serem acrescentados novos atributos com expressão artística em uma paisagem cultural, esta passa a agregar um valor artístico de novidade.

Um exemplo é a intervenção escultórica realizada na praia de San Sebastián, Espanha, em 1924, pelo artista Eduardo Chillida, denominada Peine de los Vientos. No momento de sua criação, as esculturas tinham um caráter de novidade, tanto por serem novos atributos a integrar o conjunto paisagístico, quanto pela aparência nova dos materiais. Hoje, o complexo de esculturas não possui mais um valor artístico de novidade, uma vez que no imaginário coletivo já é atributo integrante, e por isso indissociável, dessa paisagem cultural (Figura 2).

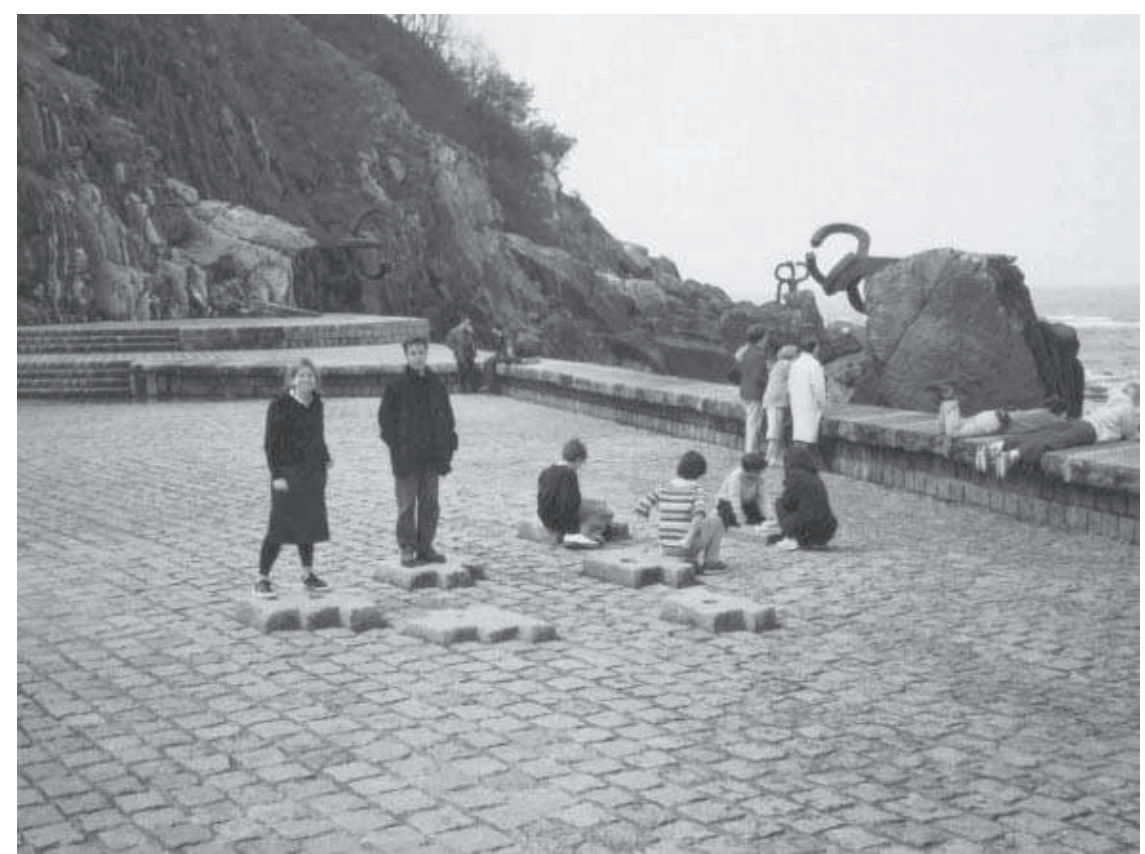

Figura 2: Conjunto Escultórico Peine de los Vientos, Espanha, 2001

Crédito: Foto de Flaviana Lira

O valor artístico relativo se refere à possibilidade de que obras de gerações anteriores possam ser apreciadas não só como testemunhos passados, mas também com respeito a sua própria e específica concepção como obra de arte. Uma paisagem cultural na qual não se reconheça um valor artístico pode passar a agregar tal valor em outro momento. Nos jardins históricos pode ser identificado um valor artístico, por serem obras concebidas com uma preocupação estética em determinado período histórico (Figura 3).

Ampliando o quadro formulado por Riegl (1999), são discutidos a seguir outros valores da paisagem cultural com base nos documentos patrimoniais e nas formulações de Delphim (2004), Lacerda (2002) e Sales (2000)5.

Ligados à dimensão natural estão os valores ecológico, biológico, botânico e horticultural, entre outros, especificamente relacionados aos atributos físicos e biológicos da paisagem cultural. A diversidade de plantas medicinais da flora amazônica, por exemplo, agrega, dentre outros, o valor botânico.

Exemplos de valores de cunho mais subjetivo resultantes da relação homem-natureza são o valor sagrado e o valor educativo. A paisagem cultural do Morro da Conceição, localizado no Recife, tem um valor de sagrado para os peregrinos. Uma paisagem cultural que agrega um valor educativo é a Praça Euclides da Cunha, criada por Burle Marx no Recife em 1935, ao reproduzir um ecossistema da caatinga para criar um jardim educativo, artístico e ecológico (Figura 4). 


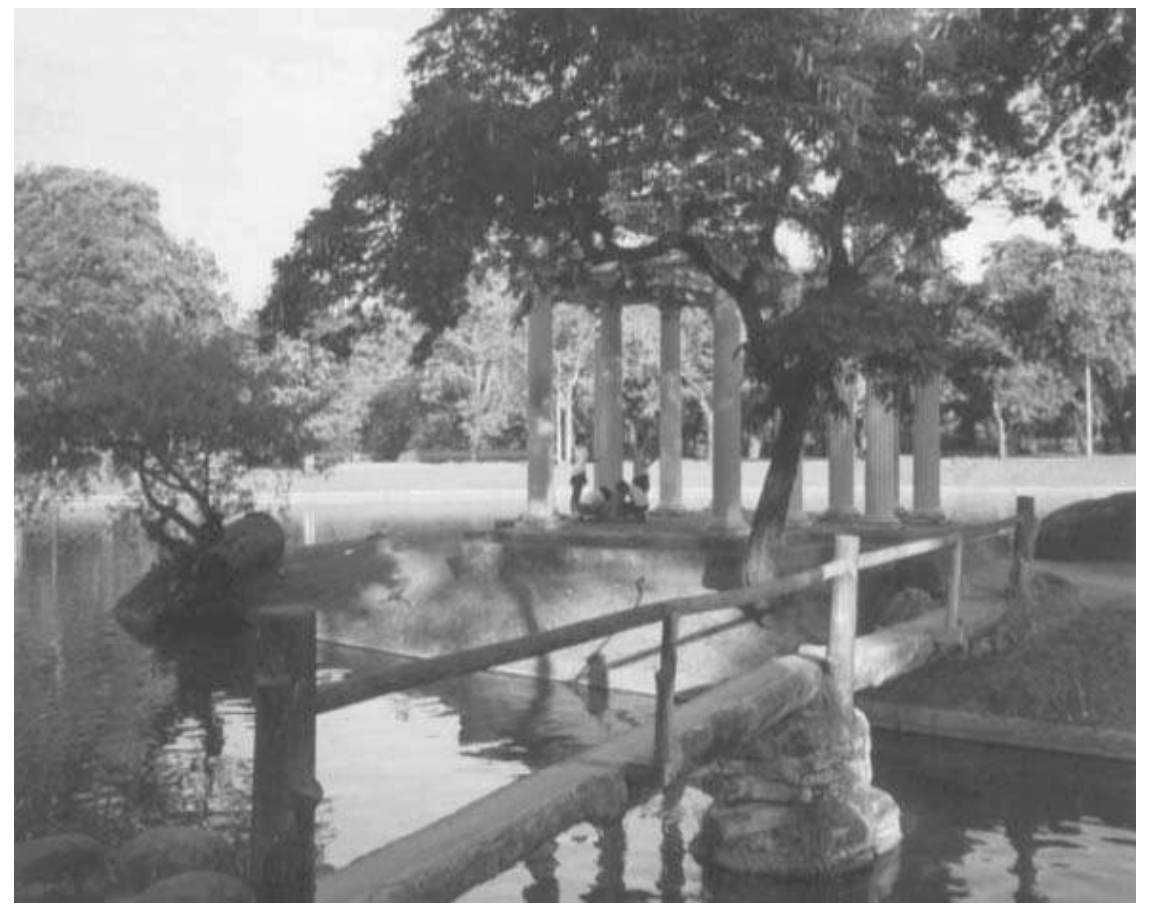

Figura 3: Quinta da Boa Vista, projeto de Glaziou, Rio de Janeiro-RJ, 2004 Crédito: Foto de Aline de Figueirôa Silva

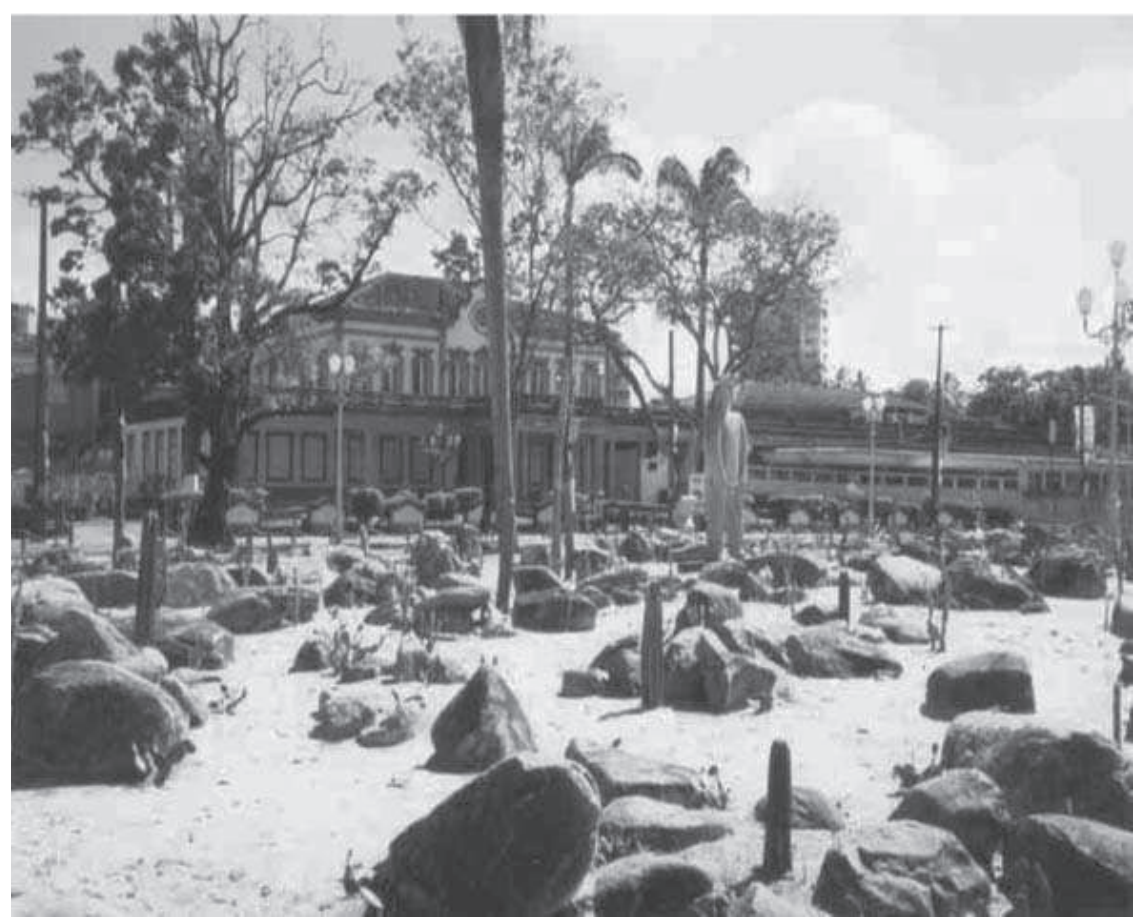

Figura 4: Praça Euclides da Cunha, projetada por Burle Marx, Recife-PE, 2004 Crédito: Foto de Aline de Figueirôa Silva

Os valores etnográficos, vinculados a grupos étnicos, e arqueológicos, por conta de vestígios materiais de antigas culturas, podem ser incluídos no que Riegl (1999) denominou de valor histórico. Ao mesmo tempo em que uma paisagem cultural pode ser representativa de um momento 304 da evolução humana, ela pode conter valores etnográficos e/ou arqueológicos, a exemplo de um sítio remanescente de Quilombos.

Vinculados à fala, tradições orais e escritas estão os valores legendário, toponímico e literário. Um valor legendário pode ser atribuído ao arquipélago de Fernando de Noronha, pois se conta 
que as pedras de Dois Irmãos teriam surgido quando um casal emergiu das águas depois de terem morrido de amor (Figura 5). O nome da cidade do Recife já revela um valor toponímico presente nos seus arrecifes naturais, que the configuraram o porto, vetor da fundação e designação da cidade (Figura 6).

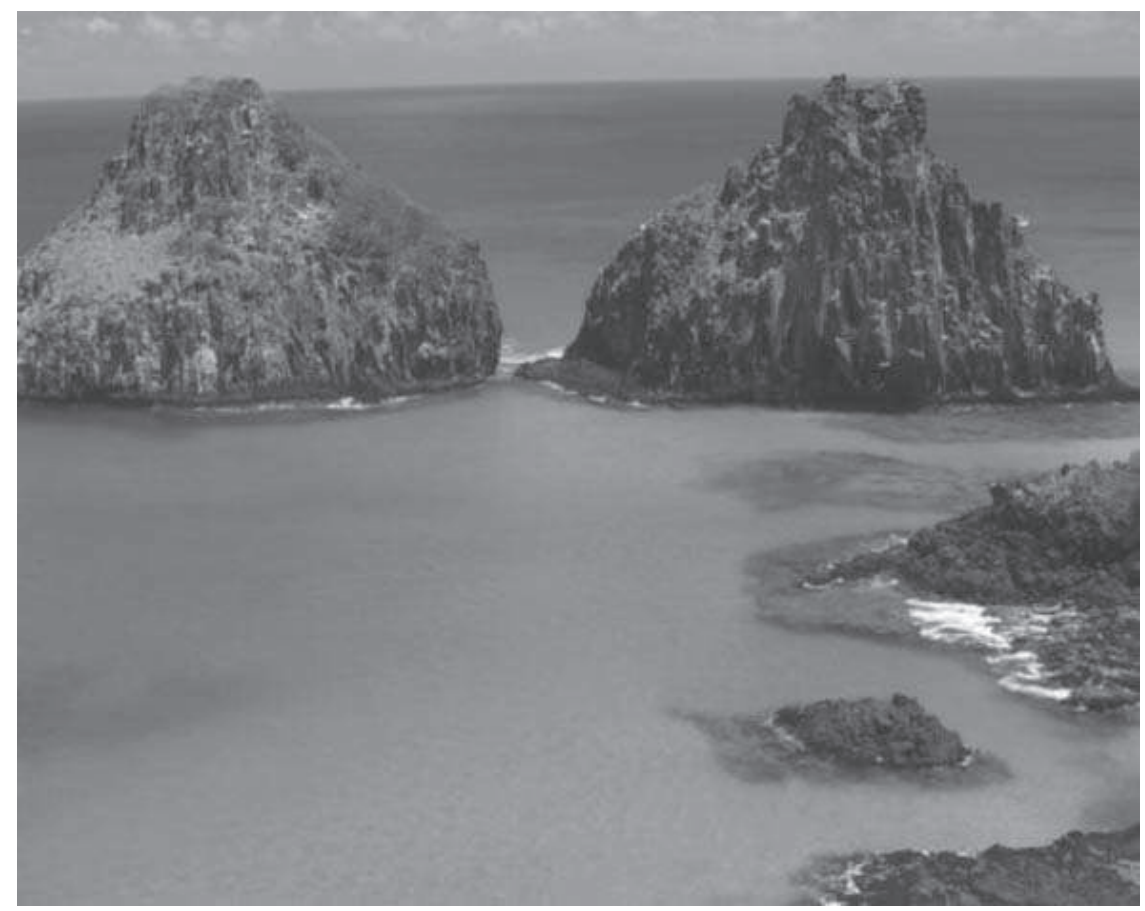

Figura 5: Pedras de Dois Irmãos, Fernando de Noronha-PE, 2005 Crédito: Foto de Flaviana Lira

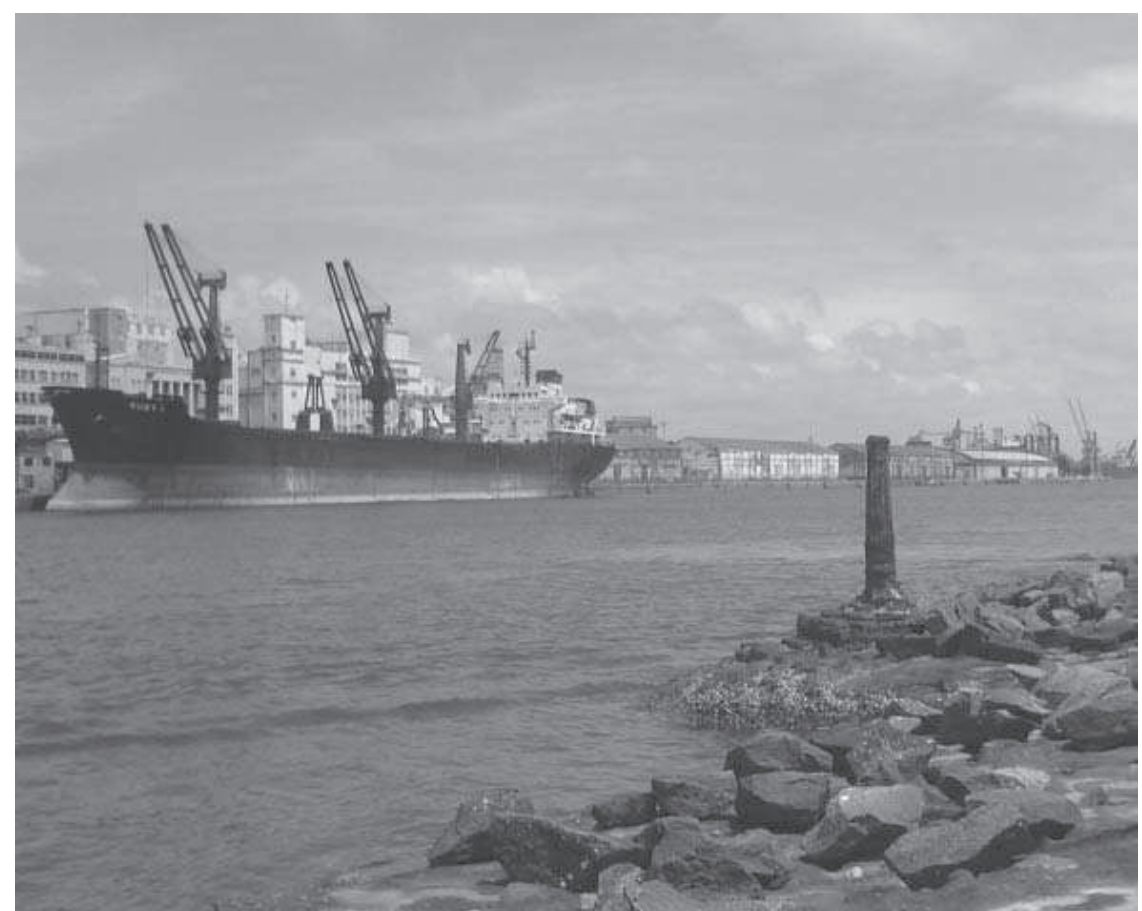

Figura 6: A cidade do Recife vista a partir dos arrecifes, Recife-PE, 2006 Crédito: Foto de Aline de Figueirôa Silva

O valor literário emerge de uma paisagem cultural quando essa estiver enraizada em narrativas, crônicas, ensaios, poemas, romances ou quaisquer outros gêneros literários. Um exemplo é o Rio 
Capibaribe no centro do Recife, que inspirou e inspira inúmeros poetas, cronistas, romancistas, ensaístas, cientistas e historiadores.

A interpretação da categorização riegliana, dos documentos patrimoniais e autores referidos, à luz da paisagem cultural, não pretendeu esgotar a multiplicidade de valores existentes. Dependendo dos atributos que caracterizam uma paisagem cultural, poderão ser identificados outros valores.

Recuperando a advertência de Lacerda (2002), estes valores não se excluem. Por exemplo, o valor artístico é também histórico já que a arte é uma criação humana como expressão de um pensamento estético em certo tempo e espaço. Um cafezal que agrega valor horticultural não abandona seu valor de uso. Por sua vez, o valor ecológico de determinada paisagem cultural não exclui o valor biológico, já que aquele seria a vida em um sistema, em um ecossistema. Ainda uma paisagem cultural configurada por um campo de cultivo de arroz, portanto expressão de um valor de uso, pode agregar um valor histórico pelas formas tradicionais de plantio e colheita. $\bigcirc$ Quadro 1, a seguir, sintetiza essa discussão.

\begin{tabular}{|c|c|}
\hline VALORES & PAISAGENS CULTURAIS \\
\hline Valor de antigüidade & A cidade de Alcântara-MA, os engenhos de cana-de-açúcar \\
\hline Valor histórico & $\begin{array}{l}\text { A cidade de Alcântara-MA, os engenhos de cana-de-açúcar, o } \\
\text { Arquipélago de Fernando de Noronha-PE }\end{array}$ \\
\hline $\begin{array}{l}\text { Valor rememorativo } \\
\text { intencionado }\end{array}$ & O Cristo Redentor no Rio de Janeiro-RJ \\
\hline Valor de uso & $\begin{array}{l}\text { Os terraços de arroz na China, a flora medicinal amazônica, o } \\
\text { Arquipélago de Fernando de Noronha-PE }\end{array}$ \\
\hline $\begin{array}{l}\text { Valor artístico de } \\
\text { novidade }\end{array}$ & As esculturas de Eduardo Chillida em San Sebastián, Espanha \\
\hline Valor artístico relativo & A Praça Euclides da Cunha no Recife-PE \\
\hline Valor ecológico & A flora medicinal amazônica, o Arquipélago de Fernando de Noronha-PE \\
\hline Valor biológico & A flora medicinal amazônica, o Arquipélago de Fernando de Noronha-PE \\
\hline Valor botânico & A flora medicinal amazônica, o Arquipélago de Fernando de Noronha-PE \\
\hline Valor horticultural & Os terraços de arroz na China, a flora medicinal amazônica \\
\hline Valor do sagrado & O Morro da Conceição, no Recife-PE \\
\hline Valor educativo & $\begin{array}{l}\text { A Praça Euclides da Cunha projetada pelo paisagista Roberto Burle Marx } \\
\text { no Recife }\end{array}$ \\
\hline Valor etnográfico & Sítios remanescentes das comunidades quilombolas \\
\hline Valor arqueológico & $\begin{array}{l}\text { Sítios remanescentes das comunidades quilombolas, cidade de Alcântara- } \\
\text { MA, os engenhos de cana-de-açúcar, o Arquipélago de Fernando de }\end{array}$ \\
\hline Valor literário & Paisagem do Rio Capibaribe no Recife-PE \\
\hline Valor legendário & O Arquipélago de Fernando de Noronha-PE \\
\hline Valor toponímico & Os arrecifes da cidade do Recife-PE \\
\hline
\end{tabular}

Quadro 1: Valores atribuídos às paisagens culturais com vistas ao seu reconhecimento como patrimônio.

Fonte: Elaborado pelas autoras, 2006 


\section{Conclusões}

A categoria "paisagem cultural", definida pela UNESCO, surgiu com o objetivo de proteger "obras conjugadas do homem e da natureza". Por isso, apesar de ser uma categoria do patrimônio mundial, é passível de ser aplicada em nível nacional e local, de modo a salvaguardar não apenas as paisagens de valor excepcional para a humanidade, mas também aquelas representativas para qualquer grupo humano.

Esta é uma categoria inexistente na legislação patrimonial brasileira. A visão patrimonial no Brasil é bastante segmentada, co-existindo separadamente a legislação de preservação cultural, abarcando os bens produzidos pelo homem, e a legislação de preservação ambiental, abarcando os recursos e ecossistemas naturais. A paisagem cultural, como categoria patrimonial, permitiria uma visão integrada do patrimônio, por abarcar os bens naturais e culturais e atingir as dimensões material e imaterial.

O entendimento da paisagem cultural como sistema formado por atributos, ao mesmo tempo em que se constitui uma unidade, permitiu a identificação de valores que podem classificá-las como patrimônio. Já que a paisagem cultural é dinâmica e seus elementos evolvem e se modificam pela ação de forças naturais e antrópicas, o foco da preservação passa a ser o conjunto de valores e não os atributos.

Assim, para reconhecer uma paisagem cultural como patrimônio de um determinado grupo humano, é necessário the conferir valores, portanto, apontar seus significados para aquele grupo. Deve ficar claro que uma paisagem cultural pode agregar qualquer um dos valores e não necessariamente todos eles para ser considerada patrimônio, afinal de contas, nas palavras de Penning-Rowsell e Lowenthal (1986), "significados e valores da paisagem variam de lugar a lugar e de uma época a outra". Considerando este aspecto particular, entende-se que não seria obrigatória ou imprescindível a classificação das paisagens culturais em tipos.

\section{Notas}

(1) O termo preservação e seus derivados são empregados ao longo do texto em sentido lato, significando salvaguarda ou proteção, equivalendo à ação de manter ou resguardar um bem de dano ou deterioração, apesar das interpretações controvertidas a que essas designações se prestam.

(2) As bases da Geografia Cultural, dentro do campo da Geografia tradicional, remontam ao século XIX quando a Geografia obteve status de ciência nas universidades. Já neste momento, o termo cultural aparece dentro de um campo de investigação da Geografia alemã, a Antropogeografia ou Geografia Humana, direcionada para o entendimento da relação entre a sociedade e seu meio. Desse modo, desde os seus primórdios a Geografia Humana já trata da cultura.

(3) A paisagem cultural será entendida, pois, como objeto que desempenha um papel memorial. Entretanto, será resguardada a expressão "monumento" por fidelidade ao texto de Riegl (1999), que, inclusive, mantém seu sentido original.

(4) A pátina é entendida como efeito deixado pela passagem do tempo nas superfícies exteriores dos elementos urbanos e nas práticas sociais ou cotidianas. É um elemento fundamental para a percepção do valor de antigüidade porque ela remete à noção da passagem do tempo e à idéia de envelhecimento e decaimento.

(5) Os documentos patrimoniais utilizados foram: A Convenção da beleza e caráter dos sítios e paisagens (1962), a Carta de Veneza (1964), a Convenção sobre a salvaguarda do patrimônio mundial, cultural e natural (1972), a Carta de Burra (1980), a Carta de Washington (1986), a Carta de Florença (1981), as Normas de Quito (1984), a Recomendação $n^{\circ}$ R Sobre a Conservação Integrada das áreas de Paisagens Culturais como integrantes das políticas paisagísticas (1995). Desses textos foram extraídos os seguintes valores: histórico, artístico e de uso (já discutidos por Riegl), além dos valores arqueológico, científico e etnográfico. Delphim (2004), além de mencionar todos estes valores, faz uma ampliação ao reconhecer o valor legendário e o valor literário da paisagem cultural, ao passo que Lacerda (2002) menciona o valor educativo (por ela designado de cognitivo ou pedagógico) e Sales ainda identifica um valor horticultural nos jardins históricos, sendo estes identificados como paisagem cultural em uma das categorias da UNESCO. A maior parte dos documentos patrimoniais não explicita a expressão "valor", muitas vezes substituída por noções como o "interesse" estético ou histórico ou a preservação "do ponto de vista" histórico ou arqueológico. Desse modo, a designação de "valor" decorre da interpretação das autoras. 


\section{Bibliografia}

BOITO, Camillo. Os restauradores. Tradução de Beatriz Mugayar Kühl. Cotia: Ateliê Editorial, 2003.

BRANDI, Cesare. Teoria da restauração. Tradução de Beatriz Mugayar Kühl. Cotia: Ateliê Editorial, 2004.

BRASIL. Constituição (1988). Constituição da República Federativa do Brasil: promulgada em 5 de outubro de 1988. Fortaleza: Banco do Nordeste do Brasil, 1988.

Decreto-lei n. 25, de 30 de novembro de 1937. Organiza a proteção do Patrimônio Histórico e Artístico Nacional. Rio de Janeiro, 30 nov. 1937. Disponível em: <http://www.iphan.gov.br/legislac/decretolei25.htm>. Acesso em: 30 jun. 2004.

CABRAL, Náiila Regane Alencar Julião; SOUZA, Marcelo Pereira de. Área de proteção ambiental: Planejamento e gestão de paisagens protegidas. São Carlos: RiMa, 2005.

CASTRO, Josué. Fatores de localização da cidade do Recife: Ensaio de geografia urbana. Brasil: Imprensa Nacional, 1948.

CHOAY, Françoise. A alegoria do patrimônio. São Paulo: Unesp, 2001.

CONNOR, Steven. Teoria e valor cultural. São Paulo: Edições Loyola, 1994.

CURY, Isabelle (Org.). Cartas patrimoniais. Rio de Janeiro: Iphan, 2000.

DELPHIM, Carlos Fernando de Moura. Considerações sobre intervenções em paisagens protegidas por seu excepcional valor. Rio de Janeiro: [s.n.], 2006. Parecer técnico.

Projetos para preservação e uso da paisagem histórica. In: ENCONTRO NACIONAL DE ENSINO DE PAISAGISMO EM ESCOLAS DE ARQUITETURA E URBANISMO, Belo Horizonte, 10 jun. 2004.

LACERDA, Norma. Os valores das estruturas ambientais urbanas: Considerações teóricas. In: ZANCHETI, Sílvio Mendes (Org.). Gestão do Patrimônio Cultural Integrado. Recife: UFPE, 2002.

MELO, Vera Mayrinck. Paisagem e simbolismo. In: ROSENDAHL, Zeny; CORRÊA, Roberto Lobato (Orgs.). Paisagem, imaginário e espaço. Rio de Janeiro: UERJ, 2001.

MENESES, Ulpiano T. Bezerra de. A paisagem como fato cultural. In: YÁZIGI, Eduardo (Org.). Turismo e paisagem. São Paulo: Contexto, 2002.

PENNING-ROWSELL, E.; LOWENTHAL, D. Landscape: Meanings and values. Londres: Allen \& Unwin, 1986.

RIEGL, Aloïs. El culto moderno a los monumentos. Madri: Visor, 1999.

ROSENDAHL, Zeny; CORRÊA, Roberto Lobato (Org). Paisagem, tempo e cultura. Rio de Janeiro: UERJ, 1998.

RÖSSLER, Mechtild. Los paisajes culturales y la convención del patrimonio mundial cultural y natural: resultados de reuniones temáticas previas. Reunión de Expertos sobre paisajes culturales en Meso América. San José, Costa Rica: Centro del Patrimonio Mundial/Oficina UNESCO para América Central, sep. 2000. Disponível em: <http://www.condesan. org/unesco/Cap\%2006\%20metchild\%20rossler.pdf>. Acesso em: jan. 2006.

RUSKIN, John. The seven lamps of architecture. Nova York: Dover Publications, 1989.

SÁ CARNEIRO, Ana Rita. A paisagem cultural e os jardins de Burle Marx no Recife. In: PONTUAL, Virgínia; SÁ CARNEIRO, Ana Rita (Orgs.). História e paisagem: Ensaios urbanísticos do Recife e de São Luís. Recife: Bagaço, 2005.

Relatório do Workshop Integrated Conservation of Territories and Landscapes of Heritage Value. 2002. Disponível em: <http://www.ceci-br.org/>. Acesso em: abr. 2003.

SALES, John. Conserving historic gardens. Journal of Architectural Conservation, v. 6, n. 2. jul. 2000. Disponível em: <http://www.historicgardens.org/articles/conserving.htm>. Acesso em: 04 dez. 2005.

UNESCO. Operational guidelines for the implementation of the World Heritage Convention. Paris: World Heritage Centre, 2005.

VIOLLET-LE-DUC, Eugène Emmanuel. Restauração. Tradução de Beatriz Mugayar Kühl. Cotia: Ateliê Editorial, 2003. 